\title{
CURCUMIN INCREASES THE SENSITIVITY OF BREAST CANCER CELLS TO TAMOXIFEN BY INHIBITING MRP2 MRNA EXPRESSION OF EFFLUX TRANSPORTER MRP2
}

\author{
DESAK GEDE BUDI KRISNAMURTI ${ }^{1}$, SEPTELIA INAWATI WANANDI ${ }^{2}$, MELVA LOUISA ${ }^{3 *}$
}

1Department of Medical Pharmacy, Faculty of Medicine, Universitas Indonesia, 2Department of Biochemistry and Molecular Biology, Faculty of Medicine, Universitas Indonesia, ${ }^{3}$ Department of Pharmacology and Therapeutics, Faculty of Medicine, Universitas Indonesia Email: melva.louisa@gmail.com

Received: 12 Dec 2018, Revised and Accepted: 10 Mar 2019

\section{ABSTRACT}

Objective: Tamoxifen is the drug of choice to treat breast cancer positive for estrogen receptor. Long-term use of tamoxifen can induce multidrug resistance (MDR) associated with decreased sensitivity of cancer cells to the drug. One of the causes of MDR is overexpression of efflux transporter multidrug resistance-associated protein (MRP)2. Various drugs are known to act as MRP2 inhibitors, including curcumin. This study investigated the effects of curcumin on the sensitivity of breast cancer cells to tamoxifen through inhibition of MRP2.

Methods: We used MCF-7 cells that were previously exposed to long-term tamoxifen treatment [MCF-7(T) cells]. MCF-7(T) cells were treated with $1 \mu \mathrm{M}$ tamoxifen, curcumin $(5,10$, and $20 \mu \mathrm{M})$, combinations of curcumin $(5,10$, and $20 \mu \mathrm{M})$ and $1 \mu \mathrm{M}$ tamoxifen, or $10 \mu \mathrm{M}$ nevirapine (a known MRP2 inhibitor) for $5 \mathrm{~d}$. Then, the cells were harvested, counted to assess cell viability, and evaluated for MRP2 mRNA expression.

Results: Treatment with curcumin alone or in combination with tamoxifen significantly reduced cell viability at all curcumin concentrations compared with the control. The reduction in cell viability was accompanied by a reduced level of MRP2 mRNA expression.

Conclusion: Application of curcumin to MCF-7 cells previously exposed to long-term tamoxifen treatment increase the sensitivity of cancer cells to tamoxifen. The increased sensitivity of these cells was attributed, at least in part, to inhibition of the efflux transporter MRP2.

Keywords: Curcumin, Tamoxifen, MRP2, Multidrug resistance

(c) 2019 The Authors. Published by Innovare Academic Sciences Pvt Ltd. This is an open access article under the CC BY license (http://creativecommons. org/licenses/by/4. 0/) DOI: http://dx.doi.org/10.22159/ijap.2019.v11s6.33553

\section{INTRODUCTION}

Tamoxifen is the drug of choice for estrogen-receptor-positive breast cancer treatment. Tamoxifen competes with estrogen for binding to the estrogen receptor [1]. Many patients who chronically use tamoxifen will eventually develop tamoxifen resistance. Resistance is a common clinical problem that leads to unsuccessful treatment. Long-term use of tamoxifen reduces the sensitivity of cancer cells to tamoxifen [2].

The issue impeding successful cancer treatment is development of multidrug resistance (MDR) against tamoxifen. MDR against chemotherapy is the phenomenon of resistance after long-term exposure to anticancer agents [3]. Several mechanisms have been proposed to mediate MDR in cancer cells. The mechanisms include loss of a cell surface receptor; specific metabolism of a drug; alteration by mutation of the specific target of the drug; and alterations in apoptosis and cell cycle processes as well as drug transporters. Alterations in drug transporters can limit accumulation of drugs within cells by limiting uptake and enhancing drug efflux [4]. One of the most common factors implicated in MDR is ATP-binding cassette (ABC) transporters; a family of membrane proteins characterized by homologous ATP-binding and transmembrane domains, which are a component of the energydependent efflux transport system [5]. ABC transporters include Pglycoprotein, breast cancer resistance protein (BCRP), and multidrug resistance-associated protein (MRP) 2 that play major roles in tamoxifen resistance [3].

Among these ABC transporters, expression of MRP2 increases in breast cancer cells because of long-term tamoxifen use. An approach to overcome this problem is to reduce excessive expression of the MRP2 transporter by administering MRP2 inhibitors.

To date, no drug targeting MDR has been clinically approved for cancer treatment. A new promising approach to enhance chemosensitivity in MDR cases is to inhibit the ABC efflux transporter. Several in vitro studies have shown that some drugs that inhibit the MRP2 transporter enhance the sensitivity of cancer cells to anticancer drugs [6]. Such drugs, such as indomethacin, ketoprofen, probenecid, and reserpine, can cause some side effects if used long term. Alternatives with minimal side effects are natural compounds. Such natural compounds include flavonoids, such as myricetin, curcumin, and quercetin, which inhibit many $A B C$ transporters [7]. These compounds have not been tested for their efficacy in tamoxifen-resistant cancer cases.

Curcumin is the active polyphenolic compound in ginger and turmeric that is common in Indonesia. Turmeric contains curcuminoid consisting of curcumin, dihydrocurcumin, desmethoxycurcumin, and bisdemethoxycurcumin [8]. Curcumin has potent effects, such as anti-inflammatory, antioxidant, and anticancer effects. The anticancer activity of curcumin induces apoptosis, inhibits activation of nuclear factor $\kappa \mathrm{B}$, and decreases the levels of proinflammatory cytokines (interleukin-6, interleukin-8, and tumor necrosis factor) [9]. In addition, tetrahydrocurcumin, a major metabolite of curcumin, inhibited the efflux function of Pglycoprotein, MXR, and MRP1 in an in vitro study related to cancer [10]. In this study, we investigated the effects of curcumin on the sensitivity of breast cancer cells to tamoxifen through inhibition of efflux transporter MRP2. A reduction in MRP2 mRNA expression is expected to reduce the amount of tamoxifen effluxed from cancer cells to increase the effectiveness of breast cancer therapy and decrease tamoxifen resistance.

\section{MATERIALS AND METHODS}

\section{Materials}

The MCF-7 cell line was obtained from The Agency for the Assessment and Application of Technology (Serpong, Indonesia). Dulbecco's modified Eagle's medium, fetal bovine serum, penicillin/streptomycin, and Fungizone were purchased from Gibco Ltd. (Singapore). Curcumin, nevirapine, and dimethylsulfoxide were purchased from Sigma-Aldrich (Singapore). Tripure isolation reagents and a LightCycler RNA Master SYBR Green I kit were purchased from Roche Diagnostics (Singapore). Primers were purchased from $1^{\text {st }}$ BASE Ltd. (Singapore). 


\section{Cell culture}

We used MCF7 cells that were previously exposed to long-term tamoxifen treatment [MCF-7(T) cells] [11]. MCF-7(T) cells were cultured in medium described in a previous study [11]. These cells were subcultured at $90 \%$ confluence. The medium was changed every day.

\section{Treatment of MCF-7(T) cells with curcumin}

MCF-7 (T) cells were treated with $1 \mu \mathrm{M}$ tamoxifen combined with curcumin $(5,10$, and $20 \mu \mathrm{M})$, and $10 \mu \mathrm{M}$ nevirapine for $5 \mathrm{~d}$. Nevirapine was used as a positive control for an MRP2 inhibitor. Tamoxifen, curcumin, and nevirapine were prepared in dimethyl sulfoxide. The medium was changed every day. Cells were harvested at $5 \mathrm{~d}$ after drug administration. Then, cell viability was analyzed by the trypan blue exclusion method. RNA was then isolated to quantify mRNA expression by quantitative real-time reverse transcription polymerase chain reaction (qRT-PCR).

\section{RNA isolation}

RNA isolation was performed using Tripure Isolation Reagents (Roche). The quantity of RNA was determined using a UV spectrophotometer at an absorbance of $260 \mathrm{~nm}$. The RNA purity index was determined by calculating the ratio of UV absorption at 260 and $280 \mathrm{~nm}$.

\section{qRT-PCR}

To analyze mRNA expression by qRT-PCR, 500 ng of RNA template was used. The mRNA expression of MRP2 was quantified by qRTPCR using a kit and primers as described previously [11, 12]. We calculated the expression level of MRP2 mRNA using the Livak method [13].

\section{Data analysis}

Data are presented as mean \pm standard deviation (SD). Graphs were created using GraphPad 7 Prism software. Differences between groups were determined using one-way ANOVA followed by the Tukey post-hoc test. $\mathrm{p}<0.05$ was considered as significant.

\section{RESULTS}

After $5 \mathrm{~d}$ of treating MCF7 (T) cells, curcumin increased the sensitivity of cells to tamoxifen (fig. 1). Curcumin at the highest concentration (20 $\mu \mathrm{M}$ ) significantly reduced the percentage of viable cells (fig. 1).

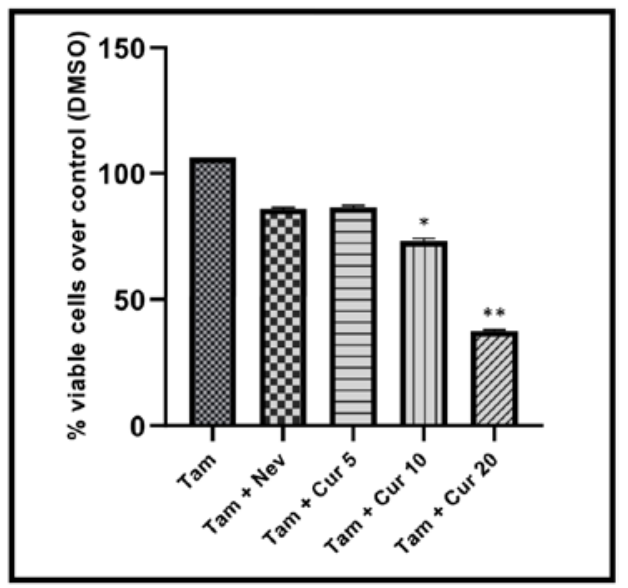

Fig. 1: Percentages of viable MCF-7 (T) cells after $5 \mathrm{~d}$ of tamoxifen treatment with or without curcumin or nevirapine. Results are presented as the mean $\pm \mathrm{SD}(\mathrm{N}=4),{ }^{*} \mathrm{p}<0.05$ versus MCF7 (T) cells. ${ }^{* *} \mathbf{p}<0.001$ versus MCF7 (T) cells

MRP2 mRNA expression was measured after $5 \mathrm{~d}$ of treatment. The addition of curcumin to tamoxifen reduced mRNA expression of MRP2 in MCF-7 (T) cells (fig. 2). Curcumin at the highest concentration $(20 \mu \mathrm{M})$ and $10 \mu \mathrm{M}$ nevirapine as the positive control resulted in a significant reduction of MRP2 mRNA expression (fig. 2).

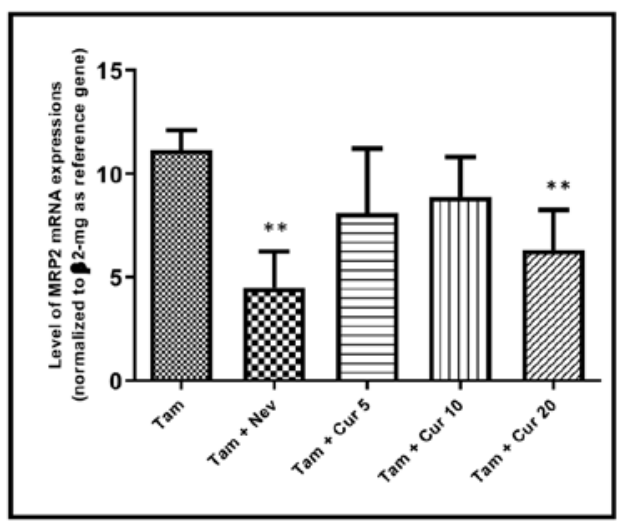

Fig. 2: MRP2 mRNA expression after MCF-7 (T) cells were treated with $1 \mu \mathrm{M}$ tamoxifen, tamoxifen with 5,10 and $20 \mu \mathrm{M}$ curcumin, or $10 \mu \mathrm{M}$ nevirapine for $5 \mathrm{~d}$. Results are presented as the mean $\pm S D(N=4) .{ }^{* *} p<0.001$ versus MCF-7 (T) cells

\section{DISCUSSION}

One of the causes of MDR is overexpression of drug transporters such as MRP2, which can increase efflux of anticancer drugs from cancer cells, thereby contributing to the failure of chemotherapy [14]. Choi et al. [15] found that tamoxifen-resistant MCF7 cells express a high level of MRP2 mRNA. The high MRP2 expression in tamoxifen-resistant MCF7 cells may result from activation of pregnane-X receptor (PXR). Their study showed that PXR activation during tamoxifen resistance is crucial to regulate MRP2 mRNA expression. In addition, they found that PI3-kinase plays a role in controlling MRP2 expression of tamoxifen-resistant MCF7 cells. Another study showed that expression of MRP2 in MCF-7 cells was increased after tamoxifen treatment for 10 passages ( $44 \mathrm{~d}$ ) [11].

In this study, we exposed tamoxifen-resistant MCF7 cells to curcumin at various concentrations $(5,10$, and $20 \mu \mathrm{M})$ or the positive control (10 $\mu \mathrm{M}$ nevirapine) combined with $1 \mu \mathrm{M}$ tamoxifen. Curcumin at the lowest concentration did not reduce the percentage of viable cells, whereas curcumin at the highest concentration significantly reduced viable cells compared with the positive control (nevirapine). Nevirapine is a non-nucleoside reverse transcriptase inhibitor that inhibits MRP2 in vitro. Cytotoxic effects of nevirapine against cancer cell lines have been reported previously [16].

Curcumin is also associated with chemoprevention by inhibiting MDR1, MRP, and BCRP efflux transporters [17].

Jiang et al. [18] showed that the combination of tamoxifen and curcumin in MCF7/ICC2 cells for $3 \mathrm{~d}$ had a synergistic effect by decreasing cell viability, and curcumin increased the sensitivity of the cells to tamoxifen.

Their study also showed that curcumin modulated cell proliferation and increased sensitivity of resistant breast cancer cells positive for the estrogen receptor to long-term tamoxifen exposure. Wortelboer et al. [19] showed that $50 \mu \mathrm{M}$ curcumin inhibited MRP1 and MRP2 transporters in MDCKII-MRP1 and MDCKII-MRP2 cells. The mechanism of MRP transporter inhibition by curcumin is still unclear. Presumably, the polyphenol content in curcumin modulates the transport processes of MRP1 and MRP2 through several mechanisms, such as the formation of a glutathione (GSH) conjugate that competitively inhibits MRP1 and MRP2, a decrease in GSH levels, and direct inhibition of MRP1 and MRP2 through MRPcurcumin interactions [19].

Based on our results, we believe that curcumin might be a promising candidate agent to reverse tamoxifen resistance in breast cancer cells with MRP2 as the target. Further research on the mechanism of 
curcumin in decreasing mRNA expression of MRP2 in breast cancer cells with long term tamoxifen treatment is still needed.

\section{CONCLUSION}

Curcumin at high concentrations can be a chemosensitizer for tamoxifen therapy. The increase in sensitivity of our cells was attributed to, at least in part, inhibition of the efflux transporter MRP2.

\section{ACKNOWLEDGMENT}

This study was supported by the Directorate of Research and Public Service, Universitas Indonesia. This article was presented at The 3rd International Conference and Exhibition on Indonesian Medical Education and Research Institute (ICE on IMERI 2018), Faculty of Medicine, Universitas Indonesia, Jakarta, Indonesia. We thank the 3rd ICE on IMERI Committee who had supported the peer review and manuscript preparation before submitting to the journal.

\section{AUTHORS CONTRIBUTIONS}

All the author have contributed equally

\section{CONFLICT OF INTERESTS}

We declare that we have no conflict of interest

\section{REFERENCES}

1. Clemons M, Danson S, Howell A. Tamoxifen ("Nolvadex"): a review. Cancer Treat Rev 2002;28:165-80.

2. Gottesman MM, Fojo $T$, Bates SE. Multidrug resistance in cancer: role of ATP-dependent transporter. Nat Rev Can 2002;2:48-58.

3. Choi CH. ABC transporter as multidrug resistance mechanism and the development of chemosensitizers for their reversal. Cancer Cell Int 2005;5:30.

4. Housman G, Byler S, Heerboth S, Lapinska K, Longacre M, Snyder N, et al. Drug resistance in cancer: an overview. Cancers (Basel) 2014;6:1769-92.

5. Chang G. Multidrug resistance ABC transporters. FEBS Lett 2003;555:102-5.

6. Wu CP, Calcagno AM, Ambudkar SV. Reversal of ABC drug transporter-mediated multidrug resistance in cancer cells: evaluation of current strategies. Curr Mol Pharmacol 2008;1:93-105.

7. Di Pietro A, Conseil G, Perez Victoria JM, Dayan G, Baubichon Cortaya H, Trompiera D, et al. Modulation by flavonoids of cell multidrug resistance mediated by $\mathrm{P}$-glycoprotein and related ABC transporters. Cell Mol Life Sci 2002;59:307-22.

8. Calabrese V, Bates TE, Mancuso C. Curcumin and the cellular stress response in free radical-related diseases. Mol Nutr Food Res 2008;52:1062-73.

9. Vallianou NG, Evangelopoulos A, Schizas N. Potential anticancer properties and mechanisms of action of curcumin. Anticancer Res 2015;35:645-52.

10. Trompier D, Baubicon Cortay H, Chang XB, Maitrjean M, Barron D, Riordan JR, et al. Multiple flavonoid-binding sites within multidrug resistance protein MRP1. Cell Mol Life Sci 2003;60:2164-77.

11. Krisnamurti DGB, Louisa M, Anggraeni E, Wanandi SI. Drug efflux transporters are overexpressed in short-term tamoxifeninduced MCF7 breast cancer cells. Adv Pharmacol Sci 2016;2016:6702424.

12. Albermann N, Schmitz Winnenthal FH, Zgraggen K. Expression of the drug transporters MDR1/ABCB1, MRP1/ABCC1, MRP2/ABCC2, BCRP/ABCG2, and PXR in peripheral blood mononuclear cells and their relationship with the expression in intestine and liver. Biochem Pharmacol 2005;70:949-58.

13. Livak KJ, Schmittgen TD. Analysis of relative gene expression data using real-time quantitative PCR and the 2- $\Delta \Delta$ CT method. Methods 2001;25:402-8.

14. Stavrovskaya A, Stromskaya TP. Transport proteins of the ABC family and multidrug resistance of tumor cells. Biochemistry 2008;73:592-604.

15. Choi HK, Yang JW, Roh SH, Han CY, Kang KW. Induction of multidrug resistance associated protein 2 in tamoxifenresistant breast cancer cells. Endocrine Related Cancer 2007;14:293-303.

16. Hecht M, Erber S, Harrer T, Klinker H, Roth T, Parsch $\mathrm{H}$, et al. Efavirenz has the highest anti-proliferative effect of nonnucleoside reverse transcriptase inhibitors against pancreatic cancer cells. PLoS ONE 2015;10:e0130277.

17. Wu CP, Ohnuma S, Ambudkar SV. Discovering natural product modulators to overcome multidrug resistance in cancer chemotherapy. Curr Pharm Biotechnol 2011;12:609-20.

18. Jiang M, Huang O, Zhang X, Xie Z, Shen A, Liu H, et al. Curcumin induces cell death and restores tamoxifen sensitivity in the antiestrogen-resistant breast cancer cell lines MCF-7/ICC2 and MCF-7/lCC9. Molecules 2013;18:701-20.

19. Wortelboer HM, Usta M, Van der Velde AE, Boersma MG, Spenkelink B, van Zanden JJ, et al. Interplay between MRP inhibition and metabolism of MRP inhibitors: the case of curcumin. Chem Res Toxicol 2003;16:1642-51. 